Niklas Brandt and Guido J. Reiss*

\title{
The twinned crystal structure of 1,3-phenylenedimethanaminium dibromide, $\mathrm{C}_{8} \mathrm{H}_{14} \mathrm{Br}_{2} \mathrm{~N}_{2}$
}

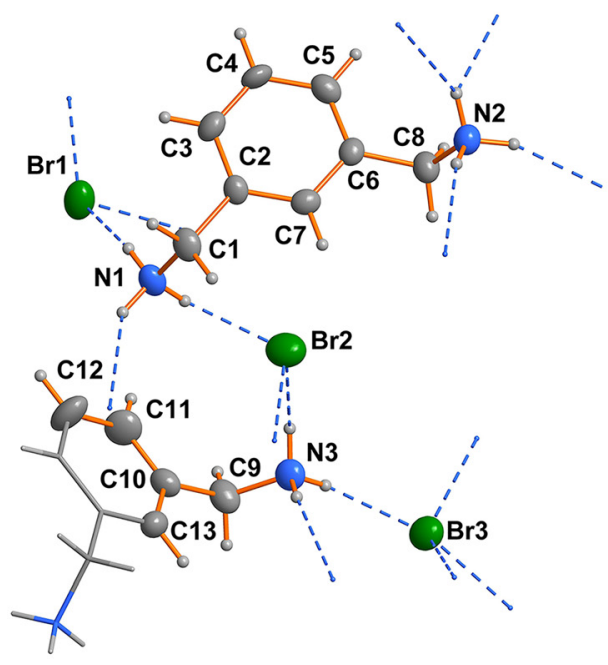

https://doi.org/10.1515/ncrs-2020-0618

Received December 2, 2020; accepted December 30, 2020; published online January 18, 2021

\section{Abstract}

$\mathrm{C}_{8} \mathrm{H}_{14} \mathrm{Br}_{2} \mathrm{~N}_{2}$, monoclinic, I2/a (no. 15), $a=9.0331(9) \AA$, $b=13.4475(14) \AA, c=27.586(3) \AA, \beta=94.879(9)^{\circ}, Z=12$, $V=3338.8(6) \AA^{3}, R_{g t}(F)=0.0582, w R_{\text {ref }}=0.0885$, $T=290 \mathrm{~K}$.

\section{CCDC no.: 2053150}

Tables 1 and 2 contain details on the crystal structure as well as measurement conditions and a list of the atoms including atomic coordinates and displacement parameters.

*Corresponding author: Guido J. Reiss, Institut für Anorganische Chemie und Strukturchemie Lehrstuhl II: Material- und Strukturforschung, Heinrich-Heine-Universität Düsseldorf, Universitätsstrasse 1, D-40225 Düsseldorf, Germany, E-mail: reissg@hhu.de. https://orcid.org/0000-0002-3004-3955 Niklas Brandt, Institut für Anorganische Chemie und Strukturchemie Lehrstuhl II: Material- und Strukturforschung, Heinrich-HeineUniversität Düsseldorf, Universitätsstrasse 1, D-40225 Düsseldorf, Germany

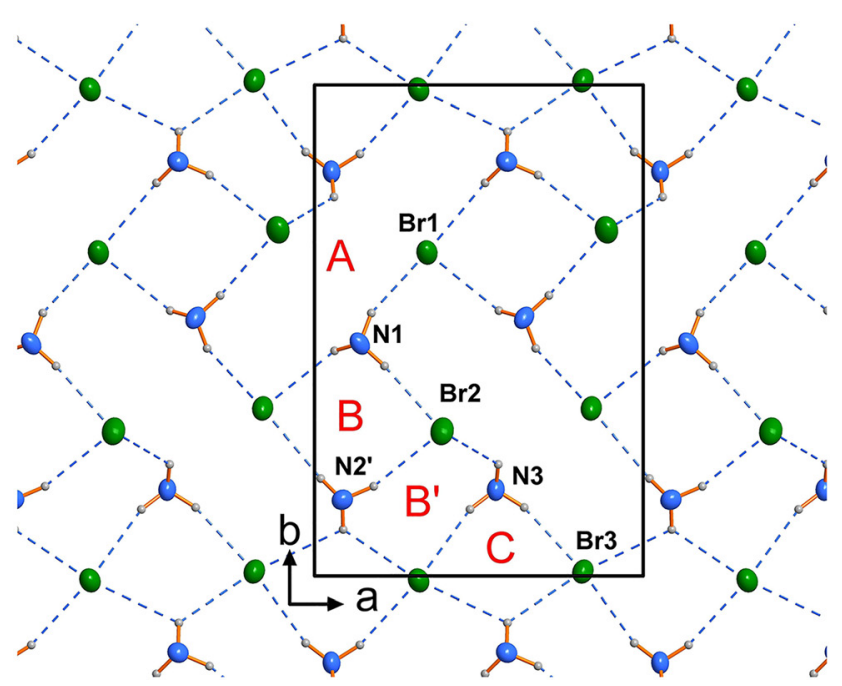

Table 1: Data collection and handling.

\begin{tabular}{|c|c|}
\hline Crystal: & Colorless needle \\
\hline Size: & $0.67 \times 0.14 \times 0.04 \mathrm{~mm}$ \\
\hline Wavelength: & Mo $K \alpha$ radiation $(0.71073 \AA)$ \\
\hline$\mu:$ & $7.24 \mathrm{~mm}^{-1}$ \\
\hline Diffractometer, scan mode: & Xcalibur, $\omega$ \\
\hline$\theta_{\max }$, completeness: & $27.0^{\circ},>99 \%$ \\
\hline$N(h k l)_{\text {measured }}, N(h k l)_{\text {unique }}$ & 9870,9870 \\
\hline Criterion for $I_{\mathrm{obs}}, N(h k l)_{\mathrm{gt}}:$ & $I_{\text {obs }}>2 \sigma\left(I_{\text {obs }}\right), 6167$ \\
\hline$N(\text { param })_{\text {refined }}:$ & 171 \\
\hline Programs: & $\begin{array}{l}\text { Diamond [1], CrysAlis }{ }^{P R O}[2] \text {, } \\
\text { SHELX [3-5] }\end{array}$ \\
\hline
\end{tabular}

\section{Source of material}

The title compound 1,3-phenylenedimethanaminium dibromide was synthesized by the reaction of $63 \%$ aqueous hydrobromic acid and 1,3-phenylenedimethanamine at ambient conditions. In a typical experiment $1 \mathrm{mmol}$ of 1,3-phenylenedimethanamine is reacted with an excess of hydrobromic acid. The resulting light-yellow solution was stored in a desiccator equipped with a small amount of molecular sieve. Clear colourless crystals were obtained after a few days. 
Table 2: Fractional atomic coordinates and isotropic or equivalent isotropic displacement parameters $\left(\AA^{2}\right)$.

\begin{tabular}{|c|c|c|c|c|}
\hline Atom & $x$ & $y$ & $z$ & $U_{\text {iso }}{ }^{*} / U_{\text {eq }}$ \\
\hline $\mathrm{Br} 1$ & $0.34206(7)$ & $0.65873(5)$ & $0.59810(3)$ & $0.0450(2)$ \\
\hline $\mathrm{Br} 2$ & $0.38821(8)$ & $0.29498(6)$ & $0.65036(3)$ & $0.0508(2)$ \\
\hline $\mathrm{Br} 3$ & $0.81651(7)$ & $0.00903(5)$ & $0.57816(3)$ & $0.0446(2)$ \\
\hline N1 & $0.1378(5)$ & $0.4737(4)$ & 0.64036 (19) & $0.0421(17)$ \\
\hline H11 & $0.173(4)$ & $0.536(2)$ & $0.6344(6)$ & $0.063^{*}$ \\
\hline $\mathrm{H} 12$ & $0.061(3)$ & 0.459 (3) & $0.6176(8)$ & $0.063^{*}$ \\
\hline H13 & $0.213(4)$ & 0.428 & $0.6384(5)$ & $0.063^{*}$ \\
\hline N2 & $0.4155(5)$ & $0.3444(4)$ & 0.87023 (19) & $0.0416(17)$ \\
\hline $\mathrm{H} 21$ & $0.320(4)$ & $0.317(3)$ & $0.8673(2)$ & $0.062^{\star}$ \\
\hline $\mathrm{H} 22$ & $0.413(4)$ & $0.405(2)$ & $0.8869(8)$ & $0.062^{\star}$ \\
\hline $\mathrm{H} 23$ & $0.481(3)$ & $0.301(3)$ & $0.8875(8)$ & $0.062^{\star}$ \\
\hline N3 & $0.5516(5)$ & $0.1762(4)$ & $0.5630(2)$ & $0.0428(18)$ \\
\hline H31 & $0.474(3)$ & $0.136(3)$ & $0.5693(6)$ & $0.064^{*}$ \\
\hline H32 & $0.558(4)$ & $0.2278(18)$ & $0.5847(8)$ & $0.064^{*}$ \\
\hline H33 & $0.638(4)$ & $0.140(3)$ & $0.5661(5)$ & $0.064^{\star}$ \\
\hline $\mathrm{C} 1$ & $0.0842(7)$ & $0.4706(5)$ & $0.6899(2)$ & 0.0418 (19) \\
\hline $\mathrm{H} 1 \mathrm{~A}$ & 0.046393 & 0.404593 & 0.695782 & $0.050^{*}$ \\
\hline H1B & 0.002849 & 0.517270 & 0.691316 & $0.050^{*}$ \\
\hline $\mathrm{C} 2$ & $0.2040(6)$ & $0.4957(5)$ & $0.7292(2)$ & $0.0321(16)$ \\
\hline $\mathrm{C} 3$ & $0.2424(7)$ & $0.5936(5)$ & $0.7388(3)$ & $0.0418(18)$ \\
\hline H3 & 0.195975 & 0.644503 & 0.720399 & $0.050^{*}$ \\
\hline $\mathrm{C} 4$ & $0.3483(8)$ & $0.6149(5)$ & $0.7752(3)$ & 0.0445 (19) \\
\hline $\mathrm{H} 4 \mathrm{~A}$ & 0.373114 & 0.680905 & 0.781768 & $0.053^{*}$ \\
\hline C5 & $0.4195(7)$ & $0.5411(6)$ & $0.8024(2)$ & $0.0420(18)$ \\
\hline $\mathrm{H} 5 \mathrm{~A}$ & 0.492474 & 0.557676 & 0.826850 & $0.050^{*}$ \\
\hline $\mathrm{C} 6$ & $0.3841(7)$ & $0.4433(5)$ & $0.7938(2)$ & $0.0336(17)$ \\
\hline $\mathrm{C} 7$ & $0.2749(7)$ & $0.4212(5)$ & $0.7569(2)$ & $0.0345(17)$ \\
\hline $\mathrm{H} 7 \mathrm{~A}$ & 0.249017 & 0.355192 & 0.750605 & $0.041^{*}$ \\
\hline $\mathrm{C} 8$ & $0.4656(7)$ & $0.3617(5)$ & $0.8211(2)$ & 0.0434 (19) \\
\hline H8A & 0.453020 & 0.300785 & 0.802428 & $0.052^{*}$ \\
\hline $\mathrm{H} 8 \mathrm{~B}$ & 0.570684 & 0.377590 & 0.824368 & $0.052^{*}$ \\
\hline $\mathrm{C} 9$ & $0.5275(7)$ & $0.2154(6)$ & $0.5133(2)$ & $0.048(2)$ \\
\hline H9A & 0.526552 & 0.160767 & 0.490372 & $0.057^{*}$ \\
\hline H9B & 0.608955 & 0.259240 & 0.507076 & $0.057^{\star}$ \\
\hline C10 & $0.3830(7)$ & $0.2718(6)$ & $0.5057(2)$ & 0.0357 (17) \\
\hline C11 & $0.3821(8)$ & $0.3735(6)$ & 0.5059 (3) & $0.057(2)$ \\
\hline $\mathrm{H} 11 \mathrm{~A}$ & 0.471775 & 0.407750 & 0.510117 & $0.069^{*}$ \\
\hline C12 & 0.250000 & $0.4268(8)$ & 0.500000 & $0.066(3)$ \\
\hline $\mathrm{H} 12 \mathrm{~A}$ & 0.249998 & 0.495945 & 0.500001 & $0.079^{\star}$ \\
\hline C13 & 0.250000 & $0.2213(7)$ & 0.500000 & $0.037(2)$ \\
\hline $\mathrm{H} 13 \mathrm{~A}$ & 0.250001 & 0.152185 & 0.500000 & $0.044^{\star}$ \\
\hline
\end{tabular}

\section{Experimental details}

A crystal of the title compound was directly selected from the mother liquor and mounted on an Xcalibur four-circle diffractometer equipped with an EOS detector [2]. An empirical absorption correction using spherical harmonics based on multi-scans was applied [2]. The structure solution, completion and the refinement, succeeded using the SHELX program system [3-5]. All investigated crystals showed a systematic non-merohedral twinning with a systematic and perfect overlap of some groups of reflections. We finally selected a crystal with an approximate twin ratio of 1:1. The twin operation is a twofold axis around 0.000, 0.707, 0.707 in the reciprocal lattice $(0.060,0.9700 .234$ for the direct lattice). The resulting twin matrix is: $-1.000,0.000,0.000$; $0.100,0.612,0.387 ; 0.100,1.613,-0.613$. Atomic coordinates of hydrogen atoms were added using the corresponding riding model with fixed $U_{\text {iso }}$ parameters. The maximum residual electron density peaks (all $>0.66 \mathrm{e} \cdot \AA^{-3}$ ) are right next to the bromide anions.

\section{Comment}

There is a longstanding interest of one of us (GJR) in the structural chemistry of diaminium salts and their hydrogen bonding schemes [6-9].

We have already shown that the lengths and shapes of organic cations influence or even determine the topology of the embedded polyhalogenide anions [6 and reference therein]. The final structural motif of such a system is a compromise between the accessible molecular conformations, hydrogen bonding and other weak intermolecular forces like van der Waals interactions of adjacent alkyl chains $[8,10]$. In presence of aryl moieties $\mathrm{CH}-\pi$ and $\pi-\pi$ interaction needs to be considered [11]. The 1,3-phenylenedimethanaminium cation is a typical cationic, semi-flexible tecton, which can form hydrogenbonded and cross-linked networks. In contrast to simple aliphatic diaminium cations the conformational adjustments are restricted to rotations about the $\mathrm{CH}_{2}$-aryl single bond (see the left part of the Figure).

There are already some 1,3-phenylenedimethanaminium salt structures listed in The Cambrige Structural Database. A small share of these structures contain simple counter anions like: chloride [12], perchlorate [13], sulfate [14], nitrate [15], tetraiodide [16], which form hydrogen bonded networks with the 1,3-phenylenedimethanaminium cation. Furthermore some 1,3-phenylenedimethanaminium salts with complex counter anions are in the focus of current research $[17,18]$ because of their physical properties.

The asymmetric unit of the title structure contains one 1,3-phenylenedimethanaminium dication in general position and another half of a 1,3-phenylenedimethanaminium dication located on a twofold axis (see the left part of the Figure). Consequently, there are three bromide counter anions in the asymmetric unit, which are all in general positions. Thus, the $Z^{\prime}$ parameter [19] is 1.5, a finding which is not uncommon in chemical crystallography [20-22]. The same situation has been reported for the directly structurally related 1,3-phenylenedimethanaminium dichloride [12]. Bond lengths and angles in the cation are in the range 
of expectations [12-18]. The 1,3-phenylenedimethanaminium cations in the title structure use their conformational flexibility by a rotation about the $\mathrm{C} 1-\mathrm{C} 2, \mathrm{C} 6-\mathrm{C} 8$ and $\mathrm{C} 9-\mathrm{C} 10$ single bonds, respectively (left part of the Figure). A dihedral angle of $-172.4(6)^{\circ}$ for the atoms N1, C2, C8, N2 in this structure leads to the wellknown [16] double hook shape of the 1,3-phenylenedimethanaminium dication. The 1,3-phenylenedimethanaminium cation located on the twofold axis shows a significantly different conformation (N3-C9-C9'-N3' $\left.=-136.9(8) ;^{\prime}=-x+1 / 2, y,-z+1\right)$.

Cations and anions are connected via $\mathrm{NH} \cdots \mathrm{Br}$ hydrogen bonds (see the Figure). Each $-\mathrm{NH}_{3}$ group donates at least three hydrogen bonds and each bromide anion accepts at least three of them. All $\mathrm{Br} \cdots \mathrm{H}$ distances are significantly below the typical van der Waals distances [23]. These hydrogen bonds construct a 2D-network in the $a b$ plane. In this network three different ring types (right part of the Figure) can be assigned (graph set descriptors [24]: $A: R_{8}^{4} 16 ; B$ and $\left.B^{\prime}: R_{4}^{2}(8), C: R_{3}^{2}(6)\right\}$.

The title structure shows the ability of semiflexible organic cations to support the formation of an ordered crystalline material by its conformational adjustments to form a maximum of hydrogen bonds.

Author contributions: All the authors have accepted responsibility for the entire content of this submitted manuscript and approved submission.

Research funding: This research was funded by the Ministry of Innovation, Science and Research of North-Rhine Westphalia and the German Research Foundation - DFG (Xcalibur diffractometer; INST 208/533-1, project no. 162659349). Finally, funding by the open access fund of the Heinrich-Heine-Universität Düsseldorf is also gratefully acknowledged.

Conflict of interest statement: The authors declare no conflicts of interest regarding this article.

\section{References}

1. Brandenburg K. DIAMOND. Visual Crystal Structure Information System. Ver. 4.5.2; Crystal Impact: Bonn, Germany, 2018.

2. Oxford Diffraction. CrysAlis ${ }^{\text {PRO }}$. (version 1.171.33.42); Oxford Diffraction Ltd.: Oxford, UK, 2009.

3. Sheldrick G. M. A short history of SHELX. Acta Crystallogr. 2008, A64, 112-122.

4. Sheldrick G. M. Crystal structure refinement with SHELXL. Acta Crystallogr. 2015, C71, 3-8.

5. Hübschle C. B., Sheldrick G. M., Dittrich B. ShelXle: a Qt graphical user interface for SHELXL. J. Appl. Crystallogr. 2011, 44, 1281-1284.

6. Megen van M., Reiss G. J. I ${ }_{6}{ }^{2-}$ Anion composed of two asymmetric triiodide moieties: a competition between halogen and hydrogen bond. Inorganics 2013, 1, 3-13.
7. Reiss G. J., van Megen M. Two new polyiodides in the 4,4'-bipyridinium diiodide/iodine system. Z. Naturforsch. 2012, B67, 5-10.

8. Reiss G. J., Engel J. S. Hydrogen bonded 1,10-diammoniodecane - an example of an organo-template for the crystal engineering of polymeric polyiodides. CrystEngComm 2002, 4, 155-161.

9. van Megen M., Jablonka A., Reiss G. J. Synthesis, structure and thermal decomposition of a new iodine inclusion compound in the 2,2-dimethylpropane-1,3-diamine $/ \mathrm{HI} / \mathrm{I}_{2}$ system. Z. Naturforsch. 2014, B69, 753-760.

10. Visi M. Z., Knobler C. B., Owen J. J., Khan M. I., Schubert D. M. Structures of self-assembled nonmetal borates derived from $\alpha, \omega$-diaminoalkanes. Cryst. Growth Des. 2006, 6, 538-545.

11. Dobrzycki L., Woźniak K. 1D vs 2D crystal architecture of hybrid inorganic-organic structures with benzidine dication. J. Mol. Struct. 2009, 921, 18-33.

12. Cheng H., Li H. (m-Phenylenedimethylene)diammonium dichloride. Acta Crystallogr. 2008, E64, 02060.

13. Guesmi A., Roisnel T., Marouani H. Featuring non-covalent interactions in $m$-xylylenediaminium bis(perchlorate) monohydrate: synthesis, characterization and Hirshfeld surface analysis. J. Mol. Struct. 2019, 1194, 66-72.

14. Guesmi A., Gatfaoui S., Roisnel T., Marouani H. mXylylenediaminium sulfate: crystal structure and Hirshfeld surface analysis. Acta Crystallogr. 2016, E72, 776-779.

15. Gatfaoui S., Dhaouadi H., Roisnel T., Rzaigui M., Marouani H. mXylylenediaminium dinitrate. Acta Crystallogr. 2014, E70, 0398-0399.

16. Reiss G. J. Crystal structure of bis(1,3-phenylenedimethanaminium) bis(triiodide) tetraiodide - water (1/2), $\mathrm{C}_{8} \mathrm{H}_{16} \mathrm{I}_{5} \mathrm{~N}_{2} \mathrm{O}$. Z. Kristallogr. NCS 2020, 235, 1047-1050.

17. Su B., Song G., Molokeev M. S., Lin Z., Xia Z. Synthesis, crystal structure and green luminescence in zero-dimensional tin halide $\left(\mathrm{C}_{8} \mathrm{H}_{14} \mathrm{~N}_{2}\right)_{2} \mathrm{SnBr}_{6}$. Inorg. Chem. 2020, 59, 9962-9968.

18. Jomaa I., Noureddine O., Gatfaoui S., Issaoui N., Roisnel T., Marouani $\mathrm{H}$. Experimental, computational, and in silico analysis of $\left(\mathrm{C}_{8} \mathrm{H}_{14} \mathrm{~N}_{2}\right)_{2}\left[\mathrm{CdCl}_{6}\right]$ compound. J. Mol. Struct. 2020, 1213, 128186.

19. Steed K. M., Steed J. W. Packing Problems: high Z' crystal structures and their relationship to cocrystals, inclusion compounds, and polymorphism. Chem. Rev. 2015, 115, 2895-2933.

20. Todd A. M., Anderson K. M., Byrne P., Goeta A. E., Steed J. W. Helical or polar guest-dependent $Z^{\prime}=1.5$ or $Z^{\prime}=2$ forms of a sterically hindered bis(urea) clathrate. Cryst. Growth Des. 2006, 6, 1750-1752.

21. Kirsop P., Storey J. M. D., Harrison W. T. A. 2-Bromo-1,3bis(bromomethyl)benzene, with $Z^{\prime}=1.5$ : whole-molecule disorder of one of the two independent molecules. Acta Crystallogr. 2006, C62, 0376-0378.

22. Lo Presti L., Soave R., Longhi M., Ortoleva E. Conformational polymorphism in a Schiff-base macrocyclic organic ligand: an experimental and theoretical study. Acta Crystallogr. 2010, B66, 527-543.

23. Hu S.-Z., Zhou Z.-H., Xie Z.-X., Robertson B. E. A comparative study of crystallographic van der Waals radii. Z. Kristallogr. CM 2014, 229, 517-523.

24. Grell J., Bernstein J., Tinhofer G. Investigation of hydrogen bond patterns. A review of mathematical tools for the graph set approach. Crystallogr. Rev. 2002, 8, 1-56. 